ported, from men of large experience, the one doing the perineal and the other the suprapubic operation, seem to show that the result obtained depends rather on the man operating than on the method chosen.

Willy Meyer writes as follows:

1. I have done outside of some eighty-five Bottini operations for prostatic enlargements, forty-one suprapubic and eight perincal prostatectomies. 2. Perineal prostatectomies: The greater number of patients were satisfied with the results; one developed recto-urethral fistula on the tenth day after operation; one had a rery obstinate perineal fistula (sus picion of prostatic cancer); two patients lost power of intercourse. 3. Suprapubic prostatectomies: Results uniformly satisfactory to the patients. No fistula; no hernia; no dribbling. Virility preserved. In patients showing complications the two-stage operation, under spinal anesthesia, is highly advised. Personally, I prefer the suprapubic to the perineal operation.

Finney writes that, owing to the great experience of and good results achicved by Dr. Young, he has for the past four or five years turned cases demanding prostatectomy over to him or his (Finney's) assistants. He sars:

My experience is based on a dozen eases operated on five or six years ago. These were about equally divided between the suprapubic and perineal methods and my results in each case were very satisfactory.

\section{Crile savs:}

In my experience in about twenty-five operations for prostat cctomy the batients themselves were pleased with the result and there is not a single instance in which there has been a rlinieal failure. That is to say, in not a single instance has the patient regretted that the operation had been performed. In most cases the patients have been very grateful for the relief afforded them.

Macdonald, of Allany, writes as follows:

I have done about eighty such operations for very different conditions. The most satisfactory results have been attained in pure hypertrophies of large size having material functional disturbances. As a rule, my patients have been greatly pleased with the results of the operation.

My own experience is limited to 25 cases. There were three deaths, all due to septic conditions (pyelonephritis and cystitis) which existed at the time of the operation, and because of which conditions the patients finally asked for operative relief. There were no postoperative sequelæ. I know of no operation which gives more general or more complete satisfaction to the patients than does prostatectomy for enlarged prostate. That malignant disease is present in a much larger percentage of cases of so-called enlarged prostate than was heretofore believed to be the case is proved by the experience of Young, the Mayos, VanderVeer, Munro, Bottomley, and others. Moreover, that a benign hypertrophy of the prostate may become malignant seems from the evidence at hand a well-nigh proved fact.

Summary.-The fatalities following prostatectomy are largely due to conditions resulting from the hypertrophy and existing at the time of the operation. Prostatectomy, in the absence of serious complications, entails a risk to life of less than 2 per cent. The death rate in enlarged prostate treated by catheterization is over 5 per cent. Prostatectomy in enlargement of the prostate adds to the average expectancy of life in these patients and adds to their enjoyment and usefulness. Malignancy is present quite often in enlargements of the prostate thought to be benign in character, and it is more than probable that benign enlargement may take on malignancy.
CONCLUSIONS.

1. The catheter treatment of enlarged prostate is, like the opium and poultice treatment of appendicitis, unsurgical and unsafe.

2. Prostatectomy, done before secondary changes have arisen, is the best treatment for enlarged prostate.

\section{HYPERTROPHY OF THE SYNOVIAL FRINGES OF THE KNEE JOIN'T.}

FURTIER OBSELVATIONS.

\section{EDVILLE GERHARDT ABBOTT, A.B., M.D.} PORTLAND, MAINE.

In an article" on "Hypertrophy of the Synovial Fringes of the Knee Joint," published in 1903, I took eredit for having done some original work in this particular field. Some time later it was brought to my notice tinat a comprehensive article on operative work on the knee joint, by Dr. Joel E. Goldthwait, which included this condition, had appeared" about one year prior to this. In $1903^{3}$ there was published an article by Drs. Charles F. Painter and William G. Erving, entitler "Lipoma Arborescens," which also treated of these hypertrophies. In 1904, Dr. Albert Hoffa, late of Berlin, Germany, presented a paper on this subject at the annual session of the American Medical Association, at Atlantic City, in which by failing to call attention to the work of others he also appeared as a pioneer.

The credit for origrinal investigation in any work sinould be given to whom it belongs, and in this case, while there might be some question as to the exact nature of the work done by the different men, credit certainly scems to belong to Dr. Goldthwait through his lucid contribution mentioned above.

In order that there may be no misunderstanding as to the character of the cases described in my article ${ }^{1}$ referred to, also as to the character of those on which the following observations were made, let it be said that no inclusion is intended of those patients in whom the condition found was that of fatty tumor, chronic arthritis, or floating cartilage. The work relates wholly to that disturbance of the knee joint in which the normal synovial fringes, situated just posterior to the patella and on the same plane as the transverse line of the joint, have become so enlarged that they interfere with joint motion.

The other pathologic changes often described with this condition-lipoma arborescens, chronic villous arthritis, and floating cartilage-while in some instances they may be an cxtension of the process, seem to me to be entirely separate, and should not be considered with it.

The difference of opinion as to the results which may be expected from conservative treatment may arise from the fact that these conditions are of a different nature, and a surgeon would most certainly be justified in stating that tumors of fat, or floating cartilages, could not be satisfactorily treated by the use of the ordinary conservative treatment for joint disturbance.

Continued observations on this subject have shown that this hypertrophy of the synovial fringes is often met by the orthopedic surgeon and, furthermore, that its treatment demands surgical interference much more

1. The Journal A. M. A., April 25, 1003

2. Trans, Amer Ortho Assn.

3. Boston Med. and Surg. Jour., Mar. 19, 1903. 
frequently than was formerly supposed. Operative treatment, however, has not proved wholly successful in all cases, since the prolonged restriction of normal joint motion following the operation has been so marked that the results have caused one to hesitate before undertaking radical measures for its relicf. In conversation, Dr. Hoffa, a short time after he had presented his views on the subject, stated that he had given up the work almost wholly for this reason. At one time my views on the subject were also in accord with the above, but subsequent work has caused them to be again altered; at present, a change in the method of operating which has produced better results has led to the conviction that operative procedures are justified in all cases which do not readily yield to conservative treatmicnt.

The cause of so much difficulty following the operation has seemed to arise from the fact that too much scar tissue, which restricted motion, followed such an extensive operation as was considered necessary at one time. The long continued after-treatment with its accompanying pain, required to establish normal motion, has chilled the ardor of both the surgeon and the patient, especially if the latter had a friend who had already submitted to the operation. Therefore, a method of accomplishing the same ultimate result was sought

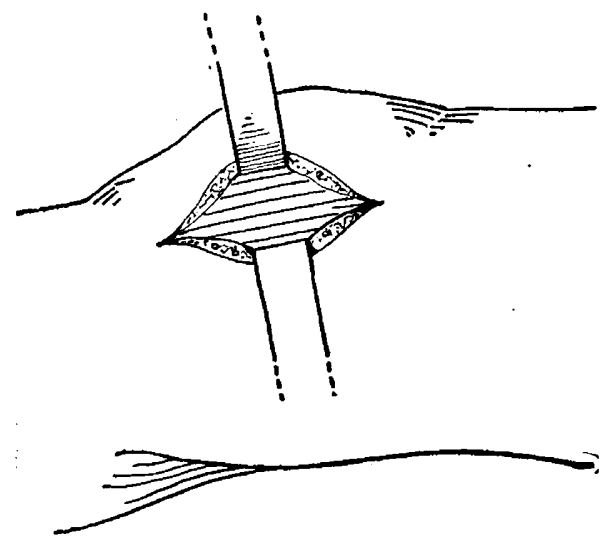

Fig. 1.- Showing capsule exposed.

with the hope of limiting the disagreeable after-symptoms.

It was with the above objection in view that I put the following procedure into effect, and the results have seemed to justify placing it before the profession:

As already stated, the usual method of operating, which is through an incision either $\mathrm{U}$-shaped or lateral, division of the capsule, and thorough removai of the offending hypertrophied fringes, has often caused serious trouble through the interference with motion by the mass of scar tissue and adhesions after the wound is healed.

The interfererce with the performance of the normal functions of the joint is due to the swollen fringes catching between the joint surfaces as the leg is extended on the thigh; and although the subjective symptoms are often severe, and the individual is rendered practically incapacitated for work, a large number of the patients, when seen for the first time, do not show marked objective symptoms, as the fringes are small, and, while the attacks are frequent with some swelling, the temporary recovery is rapid. An examination of the joint at the time of operating often shows so little enlargement of the fringes that there may be some cioubt in the opcrator's mind as to whether or not these structures are at fault. Repeated examinations, however, together with the disappearance of the symptoms following extirpation of the enlarged fringes has removed all uncertainty.

Owing to the fact that, in this class of cases, the parts which interfere with the joint motion are so small, there does not seem to 're any need of their complete removal, since they cause the disturbance wholly by projecting into the joint cavity a very little farther than they do in a normal condition. If through a more simple operation the fringes can be retracted so that the obstruction is removed, it would seem that such a procedure is advisable.

The operation which has seemed to give the best results in my hands is as follows: A small longitudinal incision about two inches in length is made on either side of the patellar tendon, through the skin and subcutaneous tissues, and the capsule of the joint is exposed. Instead of opening the joint the capsule is separated from the overlying tissues for some little

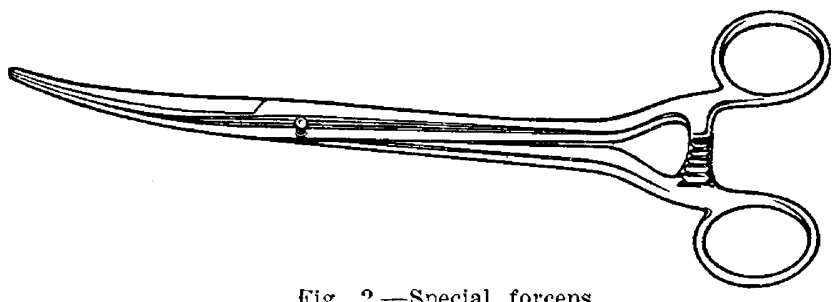
Fig. 2.-Special forceps.
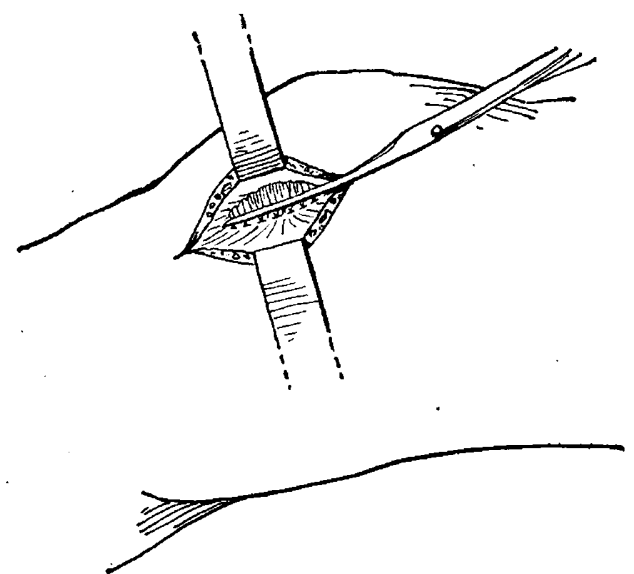

Fig. 3.-Showing forceps placed and sutures inserted.

distance laterally (Fig. 1) so that a fold may be picked $u p$ and a small plait made in it-a specially devised instrument for holding the capsule while the work is being done will be found of great service (Fig. 2). The capsule is grasped near the center of the exposed surface by a pair of volsellum forceps and the clamp is placed in position (Fig. 3). As much of the loose capsule is gathered up in this manner as is possible, for by so doing the fringes are pulled out from the joint, and the parts heal leaving them in this position. The next step in the operation is the placing of the sutures. The clamp is raised as much as possible, and sutures are passed through the capsule and synovial membrane on a line just below and parallel with the clamp. After this has been securely sewed, the capsule is cut with a pair of scissors or a knife between the clamp and the line of sutures. This leaves a cut margin nearly two inclses in length, which consists of capsular tissue on the outride with synovial membrane lining it. The edges of this cut surface should be sewed together by a fine suture 
which buries the synovial border. The skin is then closed and a splint which keeps the leg fully extended is applied.

It has been found best to keep the part in this position about one week. The whole after-treatment consists simply of placing the joint at rest until healing has taken place. Motion is not restricted by such an operation, and a few days after the removal of the splint the joint is practically normal.

The advantage of this operation over the free incision into the joint with removal of the fringes is readily seen by anyone familiar with the work, and may be summed up as follows: A large part of the danger from a more extensive operation is removed; complete recovery is better assured; and the long after-treatment with its attendant discomforts is avoided.

\section{HIP-JOINT TUBERCULOSIS: ITS EARLIER SYMPTOMS AND TREATMENT.}

WILLIAM THOMPSON BERRY, B.S., M.D.

Associate Professor of Anatomy and I'rofessor of Othopedic Surgery in Birmingham Medical College. BIRMINGHAM, ALA.

In cases of tuberculous hip, beginning insidiously, a limp is the first thing to attract the attention of the parents. It may be that this limp will disappear in two or three weeks, only to return after a varying interval up to three months. As a rule it is slowly progressive until a marked degree of disability exists.

Stiffness in the joint on the side affected may now be noticed, and any irritation of the joint causes an involuntary contraction of the muscles which resist any effort that is made to move the limb. The joint is held firm by these muscles, thus causing the pelvis to move with the limb. This museular spasm is present in many forms of inflammation of the joint, but its catchy character and persistence are the strongest points in the diagnosis of hip disease. Hyperextension and rotation are the two motions most likely to be first restricted.

Atrophy of the affected limb is an early symptom and is due to disuse and trophoneurotic disturbances. This atrophy is more noticeable in the thigh than in the calf.

shortening begins after the earlier months and gradually increases, migration of the acctabulum and bone atrophy accounting for the major part of the shortening. In the latter part of the course of the discase the foot on the affected side shows that it is smaller and shorter than the other foot, proving that it shares in the atrophic process. The paticnt often cries out during the night, especially the earlier part, because on friction of the discased parts during sleep the muscles contract sharply and quickly force together the diseased bones, causing pain. The more severe the disease the greater will be the night cries. In milder cases the child often cries out but does not awaken. Night cries indicate pain in the joint, but under conditions of non-protection, and are always referred to the joint.

l'ain in the knee joint, at the inner side, is a typical pain of early hip disease, this pain being reflex in character, as the hip joint and knee joint are supplied by the same nerve. Unless great care is exercised in your examination, a common mistake will probably occur, and you will apply treatment to the knee instead of to the hip, where the diseased area is located. An incomplete examination is often fruitful of serious and preventable disability and deformity. Local pain rarely begins until the discase has extended from the bone to the joint structures. If pain continues after you have protected a joint you may feel sure that there is some joint effusion or a burrowing abscess to be found.

Temperature is no positive index to the disease, but a high fever of 103 to $104 \mathrm{~F}$. indicates a rapidly destructive type of the infection. Even abscess formation does not affect the temperature to any appreciable degree.

The usual position in a painless case of hip discase is abduction, flexion and outward rotation, but if the infection be acute and painful the limb assumes the position of greatest self-protection, viz.: abduction, flexion and inward rotation. Badly treated cases usually result in flexion and adduction, which may be explained by the fact that the upper rim of the acetabulum becomes worn away by the intrajoint pressure, and the socket is above and behind its former site, forming a dorsal dislocation with an exaggerated adduction due to a total or partial loss of the head of the bone. Abscess may be present early in the acute form, but in milder cases only after some months, if at all.

Just behind the trochanter a fulness may be felt, even before the capsule has ruptured. When the abscess points in the adductor region, or above the crest of the jlium, it strongly indicates a perforated acetabulum. The limp, which may be intermittent, restriction of motion due to the reflex muscular spasm, pain at the inner side of knee, night cries, postural deformity of the limb, and early atrophy of the muscles of the limb, are alout the earliest symptoms of hip-joint tuberculosis. Naturally in our treatment of hip-joint disease we desire, first to prevent motion of the hip; second, to relieve pain and muscular spasm, and, third, to prevent deformity and care for abscesses as they arise.

There are in use for the treatment of an early case of hip disease a great many temporary makeshifts which I will not mention, for what we want is plenty of fresh air and sunshine along with the most effective treatment possible. One of our best means of fixation and protection of a diseased hip joint is the plaster-of-Paris spica bandage, when it is carefully and properly applied. If the discase is very active it may become necessary to keep the patient in bed for a few weeks, but if it is not very painful to the patient he may be allowed to walk about. As the activity of the disease lessens the foot need not be included in the plaster, and finally as a recovery splint the cast may extend only from the pelvis to just about the knee.

Many braces are being used, among them the Thomas hip splint, the Taylor brace and Sampson hip brace. These last two braces are employed to make traction during locomotion. The Cabot wire frame is especially adapted for use with baby patients.

Try to prevent abscesses by keeping the patient as quict as possible, if the disease seems active; but if an abscess does occur, put the patient to bed until the painful symptoms disappear. When walking, crutches may be allowed. With the system of quiet and protection nearly one-fourth of the abscesses will disappear. If an abscess seems certain to open, if left alone, it may be incised at the point most suitable for drainage. A mixed infection is shown by a fever of 102 to $103 \mathrm{~F}$., redness and heat over the abscess and an increase of the white cells of the blood, which you do not get in a tuberculous infection alone. When sinuses form, dress them as infrequently as possible.

Mechanical treatment gives the best results. Excision 